\title{
Burns from illegal cannabis oil manufacturing: a case series
}

\author{
Sarthak Sinha, Kyle Ricord MD, Patricia Harasym PhD, Jeff A. Biernaskie PhD, Duncan Nickerson MD, \\ Vincent A. Gabriel MSc MD
}

\section{Abstract}

Background: The increasing consideration of cannabis legalization in Canada and the United States has motivated physicians to assess its prospective impact on the health care system. Health care providers in the burns community are concerned about injuries sustained as a result of the illegal manufacturing of cannabis oil because it involves highly flammable reagents.

Methods: We report a retrospective case series of patients with cannabis oil burns (identified by evidence of combustion during cannabis oil manufacturing) treated from April 2012 to March 2014 at the Foothills Medical Centre in Calgary, Alberta, Canada. We compare the characteristics of these patients with those of patients admitted over the same period with any burns.

Results: We found that 12 (out of 161 patients) admitted over the review period sustained burns from cannabis oil manufacturing. Compared with patients in the total burn group, patients with cannabis oil burns were younger $(75 \%$ and $48 \%$ were younger than 41 years in the group with cannabis oil burns and the total burn group, respectively), were more likely to be male (83\% in the group with cannabis oil burns v. $74 \%$ in the total burn group) and sustained burns over a larger percentage of their total body surface area (24\% v. $9 \%$ ). Patients with cannabis oil burns also required extensive surgical management (skin grafting in $75 \%$ of cases) and spent a substantial amount of time (mean $32 \mathrm{~d}$ ) in the burn unit.

Interpretation: Burns from illegal cannabis oil manufacturing are large, require extensive management and involve younger patients than burns in general. Given that the frequency of cannabis oil burns may increase in Canada after legalization, Canadian burn centres are encouraged to monitor and report on cases with this injury mechanism.

$\mathrm{F}$ ollowing their victory in the 2015 federal election, Prime Minister Justin Trudeau and his cabinet assembled a national task force to establish a framework for cannabis legalization in Canada. A key objective of this task force was to formulate evidence-informed policy recommendations by analyzing data from jurisdictions that legalized cannabis for non-medicinal use (i.e., Colorado, Washington State). A prominent recommendation of the task force was the need to assess how changes in cannabis availability will affect public health risks in Canada and whether foreseeable changes in health care costs can be prospectively identified. ${ }^{1}$ Thus, an analysis of how cannabis legalization might affect different aspects of Canadians' health is timely, as it could guide the development of federal policy.

Here, we focus on hydrocarbon burns resulting from explosions during illegal cannabis oil manufacturing and their potential to become a growing problem in Canada. Cannabis oil (or "hash oil") is a highly potent $\delta$-9-tetrahydrocannabinol (THC) concentrate that contains up to $90 \%$ THC. ${ }^{2}$ The most common method to concentrate THC employs compressed short-chain hydrocarbons (e.g., butane, propane) as solvents. Since butane gas is heavier than the ambient air, its vapours can reach ignitable range $(2 \%-8 \%)$ and can catch fire in the presence of static electricity and open flame sources. ${ }^{2}$
People working in clandestine distilleries are particularly vulnerable to fire burns because safety measures to prevent butane vapour accumulation (i.e., fume ventilation, hazardous waste disposal) are often neglected. ${ }^{3}$ Evidence that clandestine distilleries are proliferating in North America comes from the fact that there were 3 times more butane cannabis oil confiscations between 2000 and 2007 than between 1993 and 2000. ${ }^{4}$ In addition, the increased availability of cannabis (as a result of cannabis legalization) has been associated with a significant increase in the number of patients presenting with such burns in US states like Colorado. ${ }^{5}$ Cannabis is expected to become more accessible in Canada, but the impact of this policy change on the characteristics of hydrocarbon burns is not known. The aim of this investigation is to characterize cannabis

Competing interests: Duncan Nickerson has been a consultant to ConvaTec. No other competing interests were declared.

This article has been peer reviewed.

Correspondence to: Vincent Gabriel, vince.gabriel@ albertahealthservices.ca

CMAJ Open 2018. DOI:10.9778/cmajo.20170105 
oil burns in Canadian patients by reporting a case series. We asked whether the distribution of cannabis oil burns in patients admitted to hospital differed with respect to sex, age, percentage of total body surface area burned, and time spent in hospital when compared with total burns in patients admitted over the same period.

\section{Methods}

\section{Retrospective chart review}

We performed a retrospective chart review of all patients with burns admitted to the Calgary Firefighters Burn Treatment Centre at the Foothills Medical Centre in Alberta, Canada, from April 2012 to March 2014. In each chart we first reviewed the description of the event that resulted in the burn, and patients with cannabis oil burns were identified where there was evidence of combustion during cannabis oil manufacturing. We then reviewed the chart for age, sex, burn anatomical site, percentage of total body surface area burned, burn depth, surgical procedures performed, admission duration and postdischarge outcome. No patient records were excluded from the audit.

\section{Statistical analysis}

Descriptive statistical analysis was performed using GraphPad Prism version 4.0 for Windows, and no samples were excluded from the data set.

\section{Ethics approval}

This study was approved by the Conjoint Health Research Ethics Board at the University of Calgary. The need for informed consent was waived by the institution.

\section{Results}

\section{Case series}

Our chart audit found that $12(7.5 \%)$ out of 161 patients admitted to hospital with burns over the review period sustained their burns from cannabis oil manufacturing. Of these 12 patients, 10 were brought to the hospital by ground ambulance, 1 arrived by air ambulance, and 1 was brought in by the local police (Table 1). In the total burn group, the most frequent age category of burn victims was $41-50$ years (19\%), whereas 9 of the patients with cannabis oil burns (75\%) were under the age of 41 years (Figure 1A). Men constituted $83 \%$ of patients in the cannabis oil burn group compared with $74 \%$ in the total burn group (Figure 1B). The mean percentage of total body surface area burned in patients with cannabis oil burns was $24 \%$ (interquartile range [IQR] $8-37$, range $3 \%-70 \%$ ) compared with $9 \%$ (IQR 2-11, range $0.5 \%-70 \%$ ) for patients in the total burn group (Figure 1C, Table 1). The mean admission duration for patients with cannabis oil burns was 32 days (IQR 19-49, range 3-69 d) and it was 17 days (IQR 5-19, range 1-138 d) for patients in the total burn group (Figure 1D, Table 1). The face (67\%) and hand (67\%) were the most frequently inflicted anatomical sites in patients with cannabis oil burns whereas burns to the face (31\%) and hand $(28 \%)$ were most frequent in the total burn group (Figure 1E, Table 1). Surgical débridement followed by splitthickness skin graft were required in $9(75 \%)$ patients with cannabis oil burns. Inhalation injuries were sustained by 3 (25\%) patients with cannabis oil burns, and 1 patient succumbed to his injuries. The patient who succumbed to his injuries had suffered a major burn (70\% total body surface area burned) and required decompressive laparotomy for abdominal compartment syndrome (Table 1).

\section{Interpretation}

Cannabis oil is isolated from Cannabis vegetation to concentrate THC. This extraction requires raw cannabis to be boiled in volatile solvents such as butane. Since extractions are currently performed in nonregulated distilleries, improper butane ventilation leaves workers vulnerable to fire burns from explosions. This risk is substantially exacerbated if evaporation is hastened by heating the butane-cannabis mixture on a heat source. We sought to characterize cannabis oil burns in a series of patients and discuss the potential impact of the proposal to legalize cannabis in Canada by July $1,2018,{ }^{6}$ on the characteristics of these injuries. This study reports a Canadian case series and a literature review in which we pooled findings from 6 case series to highlight emerging trends. In our case series, we describe 12 patients who sustained burns from cannabis oil manufacturing over a 2 -year period. These patients were younger, sustained burns over a larger percentage of their total body surface area and spent more days in the hospital than patients in the total burn group (Figure 2).

The clinical presentation described in our case series is consistent with previously published reports., ${ }^{3,5-9} \mathrm{We}$ found converging evidence from 190 reported cases of patients with cannabis burns suggesting that (a) these patients were young (mean $43 \mathrm{yr}$ ), (b) men were overrepresented (male to female ratio 9.6:1), (c) the patients sustained burns over a large percentage of their total body surface area $(23.9 \%)$, (d) they required extensive surgical management (skin grafting in $55.3 \%$ of cases) and (e) they spent a significant amount of time (mean $28.3 \mathrm{~d}$ ) in the burn unit. ${ }^{3,5,7-9}$ To place these findings in context, for the 205033 burn cases reported from 96 hospitals in the American Burn Association's National Burn Repository (NBR) from 2006 to 2015, the male to female ratio was 2.1:1. Although an average percentage of total body surface area burned was not reported, more than $75 \%$ of total burn sizes in this data set were less than $10 \%$ of total body surface area and $90 \%$ of all cases had a burn surface area of $20 \%$ or less. The average length of stay was around 9 days. ${ }^{10}$ Our findings for cannabis oil burns are consistent with previously published reports on burns associated with other illicit drugs. For example, methamphetamine production requires mixing volatile chemicals that can inflict burn injuries from explosions and chemical spills. Patients with these burns were also young (mean $32 \mathrm{yr}$ ), males were overrepresented by a similar proportion (male to female ratio 10.3:1), and the average percentage of total body surface area burned was $18.9 \%{ }^{11}$ 


\begin{tabular}{|c|c|c|c|c|c|c|}
\hline $\begin{array}{l}\text { Case } \\
\text { no. }\end{array}$ & $\begin{array}{l}\text { Burn } \\
\text { sites }\end{array}$ & $\begin{array}{l}\text { Burn } \\
\text { depth }\end{array}$ & \%TBSA & Surgery & $\begin{array}{l}\text { Admission } \\
\text { duration } \\
\text { (d) }\end{array}$ & Outcome \\
\hline 1 & $\begin{array}{l}\mathrm{L} \\
\mathrm{A}\end{array}$ & $\begin{array}{l}\text { FT, DPT } \\
\text { SPT }\end{array}$ & 14.75 & $\begin{array}{l}\text { EOB (legs) } \\
\text { STSG (thighs) }\end{array}$ & 24 & DC to jail \\
\hline 2 & $\begin{array}{l}\text { A } \\
\text { L } \\
\text { H (left) }\end{array}$ & $\begin{array}{l}\text { S-DPT } \\
\text { S-DPT } \\
\text { DPT }\end{array}$ & 10 & EOB (left arm) & 16 & DC home \\
\hline 3 & $\begin{array}{l}\mathrm{F}, \mathrm{N} \\
\mathrm{H} \text { (left) } \\
\mathrm{H} \text { (right) } \\
\mathrm{I}\end{array}$ & $\begin{array}{l}\text { DPT } \\
\text { DPT } \\
\text { DPT }\end{array}$ & 12 & $\begin{array}{l}\text { EOB on hands (bilateral) } \\
\text { STSG (from thighs) } \\
\text { EOB (anterior scalp and face) }\end{array}$ & 38 & DC home \\
\hline 4 & $\begin{array}{l}A \\
L \\
B \\
F \\
\end{array}$ & $\begin{array}{l}\text { FT } \\
\text { FT } \\
\text { FT } \\
\text { DPT }\end{array}$ & 70 & $\begin{array}{l}\text { DL } \\
\text { Allograft } \\
\text { STSG (from scalp) }\end{array}$ & 29 & Died in hospital \\
\hline 5 & $\begin{array}{l}\text { RUE } \\
\text { LUE } \\
\text { C/Abdomen } \\
\text { H/W (right) } \\
\text { H/W (left) } \\
\text { F (right) } \\
F \text { (left) } \\
N \\
T\end{array}$ & $\begin{array}{l}\text { FT, DPT } \\
\text { FT, DPT } \\
\text { FT } \\
\text { FT } \\
\text { FT } \\
\text { FT } \\
\text { FT } \\
\text { DPT } \\
\text { SPT }\end{array}$ & 27 & $\begin{array}{l}\text { Escharotomies (bilateral UE) } \\
\text { EOB (right arm/hand/wrist) } \\
\text { STSG (from right thigh and calf) } \\
\text { EOB (left arm/hand/wrist) } \\
\text { STSG (from left thigh and calf) } \\
\text { STSG (C and abdomen) }\end{array}$ & 52 & DC home \\
\hline 6 & $\begin{array}{l}\mathrm{H} \text { (right) } \\
\mathrm{H} \text { (left) } \\
\mathrm{F}\end{array}$ & $\begin{array}{l}\text { DPT, SPT } \\
\text { DPT, SPT } \\
\text { SPT }\end{array}$ & 5 & $\begin{array}{l}\text { EOB (bilateral hands) } \\
\text { EOB (right arm/hand/wrist) }\end{array}$ & 20 & DC home \\
\hline 7 & $\begin{array}{l}\mathrm{H} \text { (right) } \\
\mathrm{H} \text { (left) } \\
\mathrm{F}\end{array}$ & $\begin{array}{l}\text { FT } \\
\text { FT } \\
\text { DPT, SPT }\end{array}$ & 7 & $\begin{array}{l}\text { EOB (bilateral hands) } \\
\text { EOB (right arm/hand/wrist) }\end{array}$ & 20 & DC home \\
\hline 8 & $\begin{array}{l}\mathrm{F} \\
\mathrm{H}\end{array}$ & $\begin{array}{l}\text { SPT } \\
\text { DPT, SPT }\end{array}$ & 3 & & 3 & DC home \\
\hline 9 & $\begin{array}{l}\text { T, L (right) } \\
\text { T, L (left) } \\
\text { RUE } \\
\text { LUE } \\
\text { F,N }\end{array}$ & $\begin{array}{l}\text { DPT, SPT } \\
\text { DPT, SPT } \\
\text { DPT, SPT } \\
\text { DPT, SPT } \\
\text { SPT }\end{array}$ & 25 & $\begin{array}{l}\text { EOB (arms/hands/legs) } \\
\text { STSG (bilateral legs) }\end{array}$ & 18 & DC home \\
\hline 10 & $\begin{array}{l}\text { F,N } \\
\text { B } \\
\text { RUE } \\
\text { LUE } \\
\text { H,W (right) } \\
\text { H,W (left) }\end{array}$ & $\begin{array}{l}\text { FT } \\
\text { FT } \\
\text { FT } \\
\text { FT } \\
\text { FT } \\
\text { FT }\end{array}$ & 53.5 & $\begin{array}{l}\text { Fascitomy (bilateral arms and hands) } \\
\text { EOB (left arm/shoulder/hand/wrist) } \\
\text { STSG (bilateral LE) } \\
\text { EOB (bilateral shoulders/back/ } \\
\text { buttocks) } \\
\text { STSG (from neck/back/buttocks) } \\
\text { EOB (scalp/face/neck) } \\
\text { STSG (chest/head/feet) }\end{array}$ & 69 & DC home \\
\hline 11 & $\begin{array}{l}\text { F,N } \\
\text { B } \\
\text { RUE } \\
\text { LUE } \\
\text { H,W (right) } \\
\text { H,W (left) } \\
\text { L } \\
\text { I }\end{array}$ & $\begin{array}{l}\text { FT } \\
\text { FT } \\
\text { FT } \\
\text { FT } \\
\text { FT } \\
\text { FT } \\
\text { SPT }\end{array}$ & 40 & $\begin{array}{l}\text { EOB (left hand/wrist) } \\
\text { STSG (left hand/wrist) } \\
\text { EOB (face/scalp/neck) } \\
\text { STSG (chest) } \\
\text { EOB (bilateral UE) }\end{array}$ & 53 & DC home \\
\hline 12 & $\begin{array}{l}\mathrm{H} \\
\mathrm{F}, \mathrm{N} \\
\mathrm{C} \\
\mathrm{A} \text { (right) } \\
\mathrm{A} \text { (left) }\end{array}$ & $\begin{array}{l}\text { FT } \\
\text { SPT } \\
\text { SPT } \\
\text { SPT } \\
\text { SPT }\end{array}$ & 15 & $\begin{array}{l}\text { EOB (bilateral hands/forearms) } \\
\text { STSG (left thigh) }\end{array}$ & 38 & $\begin{array}{l}\text { Transferred to } \\
\text { another hospital }\end{array}$ \\
\hline
\end{tabular}

Note: $\mathrm{A}=$ arm, $\mathrm{B}=$ back, $\mathrm{C}=$ chest, $\mathrm{DC}=$ discharged, $\mathrm{DL}=$ decompressive laparotomy, $\mathrm{DPT}=$ deep partial thickness, EOB = excision of burns, $\mathrm{F}=$ face, $\mathrm{FT}=$ full thickness, $\mathrm{H}=$ hand, $\mathrm{I}=$ inhalation injury, $\mathrm{L}=$ leg, $\mathrm{LE}=$ lower extremity, $\mathrm{LUE}=$ left upper extremity, $\mathrm{N}=$ neck, RUE $=$ right upper extremity, S-DPT = superficial-deep partial thickness, SPT = superficial partial thickness, STSG $=$ split thickness skin graft, $T=$ thigh, $\%$ TBSA = percentage of total body surface area burned, UE = upper extremity, $\mathrm{W}=$ wrist. 
Of particular concern is that the frequency of cannabis oil burns may increase in Canada after legalization because of an increase in cannabis accessibility. Evidence for this concern comes from longitudinal retrospective chart reviews that found that liberalization of cannabis policies by US states was correlated with a substantial increase in the number of patients presenting with cannabis oil burns. ${ }^{3,5}$ There are two suspected reasons for this increase. First, the market value of butane cannabis oil is significantly higher than that of trimmed cannabis buds (US\$700 per ounce v. about US\$120 per ounce). ${ }^{5}$ Second, the perceived ease of extraction tempts people to set up their own distillation apparatus without exercising appropriate caution.

\section{Limitations}

Our study has 2 main limitations. First, the frequency of cannabis oil burns may be underestimated as our case series only captures records of patients who were truthful about their cause of injury or where the police were able to confirm the cause of the explosion. This problem is common to reports describing illegal drug manufacturing. ${ }^{7,8}$ In a case series from New Zealand, the authors found that only 2 out of 9 patients confessed to cannabis oil extraction being the cause of their injury on their own. ${ }^{7}$ Second, it is possible that we missed minor injuries that were not referred to our tertiary burn clinic, which might weaken our finding that cannabis oil burns are more severe than burns in general.
A

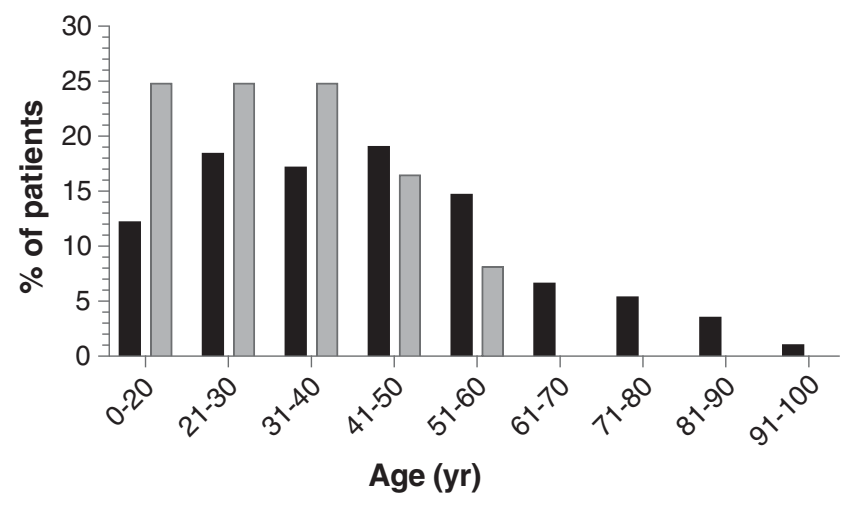

D

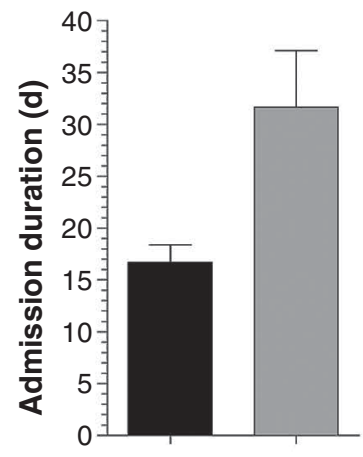

E
B

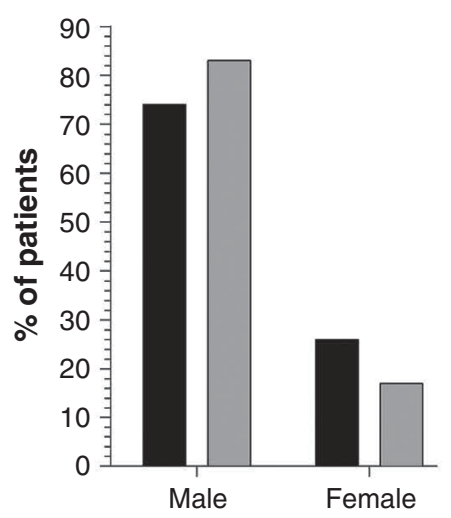

C

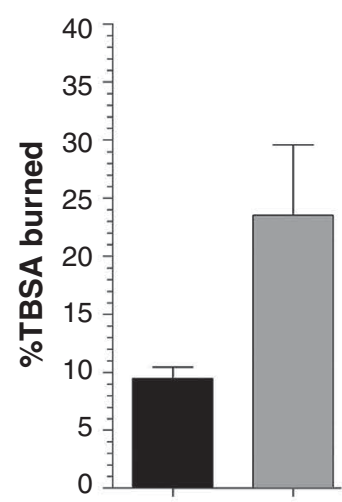

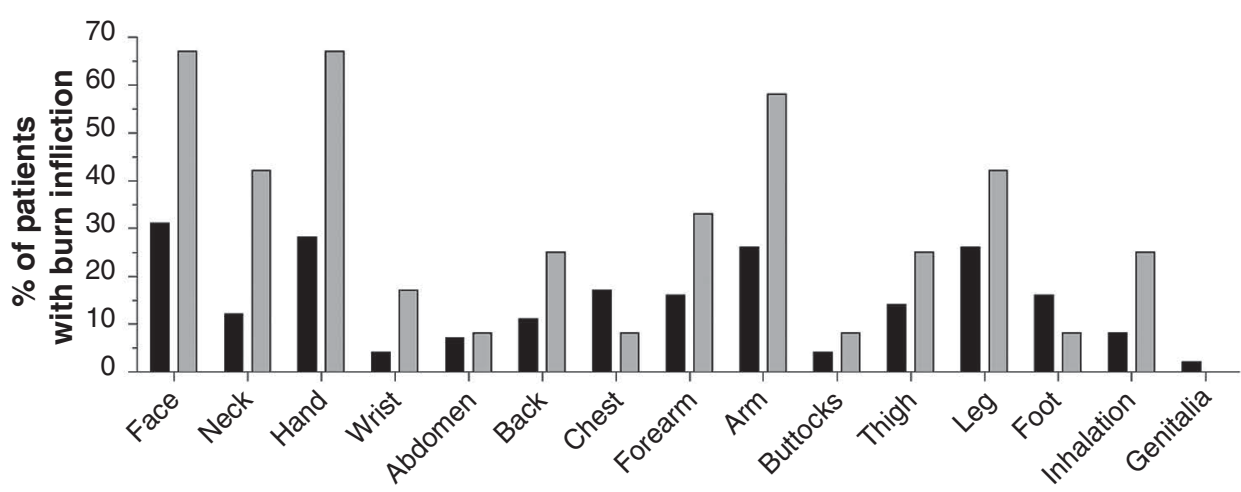

Anatomical site

$\square$ Total burns $\square$ Cannabis oil burns

Figure 1: Comparison of features of 12 patients with cannabis oil burns with those of 161 adult patients admitted to hospital with any burn over the 2-year review period. The age distribution of patients with cannabis oil burns was compared with that of the total burn population by plotting the frequency of patients falling within each identified 10-year age range (A). The sex distribution highlights a bias toward male burn victims, and this bias is especially pronounced in the cannabis oil burn group (B). Patients with cannabis oil burns on average sustained a significantly higher \%TBSA (percentage of total body surface area) burned (C) and spent more days in the burn unit (D) than patients in the total burn group. Anatomical sites inflicted with burns were compared between the two groups by plotting the percentage of patients who sustained burns at various sites (E). Error bars represent standard error of the mean. 


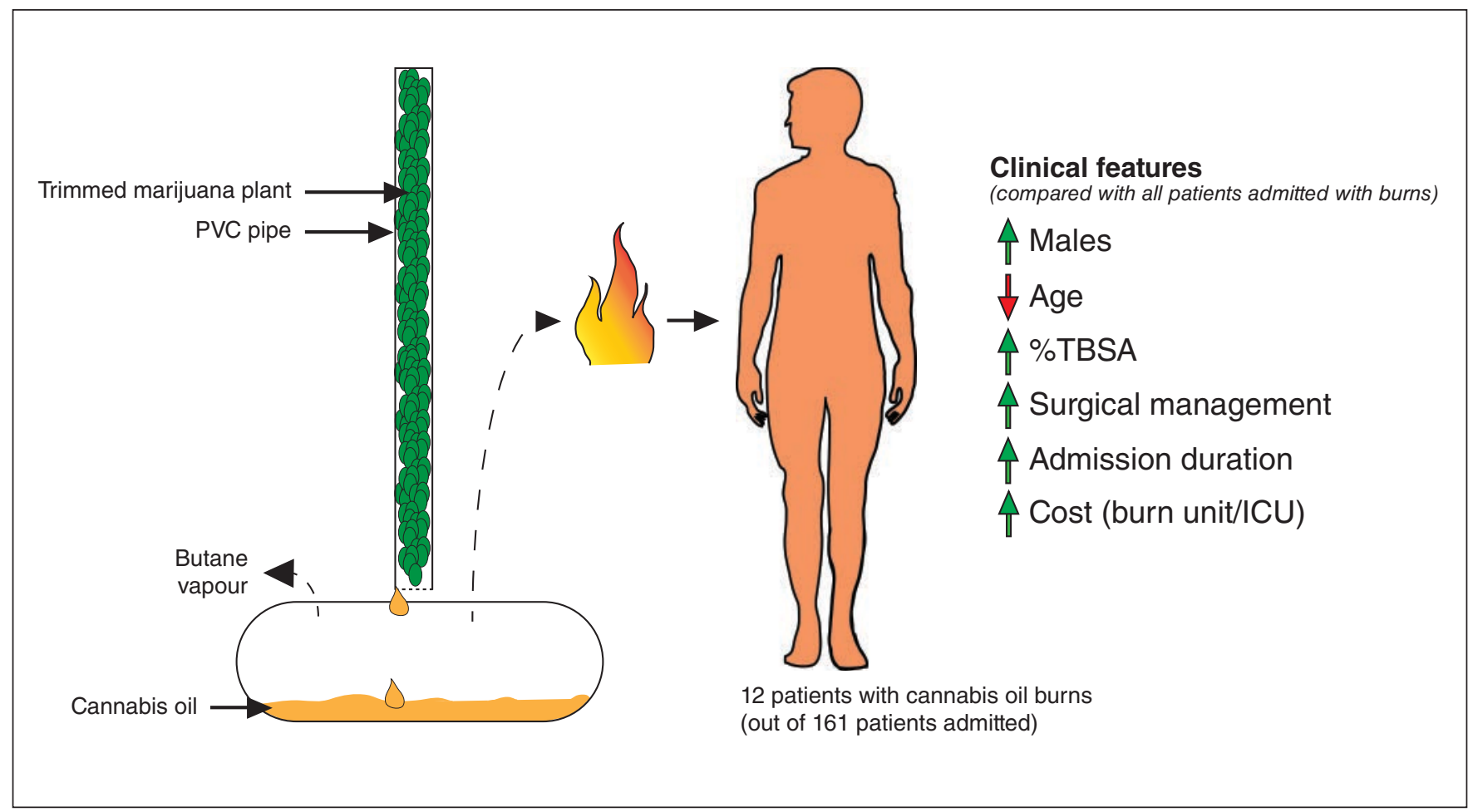

Figure 2: Schematic summary of cannabis oil extraction from cannabis trimmings and clinical features of patients with cannabis oil burns as identified from the 12 cases reported in this case series. ICU = intensive care unit; \%TBSA = percentage of total body surface area.

\section{Conclusion}

Burns from illegal cannabis oil manufacturing are large, require extensive management, and target a younger demographic. Canadian burn centres are encouraged to initiate prospective monitoring of injuries related to cannabis oil and promptly report trends to federal and provincial public health surveillance officials. Changes in the frequency and demographics of burn patients presenting with this type of injury can be assessed by establishing a baseline using retrospective reviews similar to ours.

\section{References}

1. Task Force on Cannabis Regulation and Legalization. Framework for the legalization and regulation of cannabis in Canada: the final report of the task force on. Ottawa: Health Canada; 2016.

2. Raber JC, Elzinga S, Kaplan C. Understanding dabs: contamination concerns of cannabis concentrates and cannabinoid transfer during the act of dabbing. 7 Toxicol Sci 2015;40:797-803.

3. Jensen G, Bertelotti R, Greenhalgh D, et al. Honey oil burns: a growing problem. 7 Burn Care Res 2015;36:e34-7.

4. Mehmedic Z, Chandra S, Slade D, et al. Potency trends of $\Delta 9-T H C$ and other cannabinoids in confiscated cannabis preparations from 1993 to $2008 . \mathcal{F}$ Forensic Sci 2010;5 5:1209-17.

5. Bell C, Slim J, Flaten HK, et al. Butane hash oil burns associated with marijuana liberalization in Colorado. 7 Med Toxicol 2015;11:422-5.

6. Cochrane D. Liberals to announce marijuana will be legal by July 1, 2018. CBC News. 2017 Mar. 26. Available: www.cbc.ca/news/politics/liberal-legal-marijuana -pot-1.4041902 (accessed 2017 Mar. 27).

7. Porter CJW, Armstrong JR. Burns from illegal drug manufacture: case series and management. 7 Burn Care Rebabil 2004;25:314-8.

8. Romanowski KS, Barsun A, Kwan P, et al. Butane hash oil burns: a 7-year perspective on a growing problem. 7 Burn Care Res 2017;38:e165-71.

9. Monte AA, Zane RD, Heard KJ. The implications of marijuana legalization in Colorado. 7AMA 2015;313:241-2.

10. National Burn Repository (NBR). Chicago: American Burn Association. n.d. Available: http://ameriburn.org/research/obtaining-burn-data/ (accessed 2018 Jan. 13).
11. Danks RR, Wibbenmeyer LA, Faucher LD, et al. Methamphetamineassociated burn injuries: a retrospective analysis. 7 Burn Care Rehabil 2004; 25:425-9.

Contributors: Sarthak Sinha synthesized the literature review, analyzed the data, designed the figures and co-wrote the manuscript with Kyle Ricord and Vincent Gabriel. Kyle Ricord and Patricia Harasym audited charts over a 2-year review period at the Foothills Medical Centre in Alberta, Canada. Jeff Biernaskie, Duncan Nickerson and Vincent Gabriel were responsible for conception, design and supervision of the project, providing ongoing critical feedback. All authors critically revised the manuscript, gave final approval of the version to be published and agreed to act as guarantors of the work.

Affiliations: Departments of Clinical Neurosciences, Pediatrics and Surgery (Sinha, Ricord, Harasym, Gabriel, Nickerson), Faculty of Medicine, University of Calgary; Department of Comparative Biology and Experimental Medicine (Sinha, Harasym, Biernaskie), Faculty of Veterinary Medicine, University of Calgary; Calgary Firefighters Burn Treatment Society (Nickerson, Gabriel), Calgary, Alta.

Acknowledgements: The authors thank Waleed Rahmani for providing critical feedback on the manuscript and figures. They also thank Christie Hurrell from the Taylor Family Digital Library (University of Calgary) for assistance with the Open Access Authors Fund.

Funding: This work was funded by an Alberta Innovates (AI) Collaborative Research and Innovation Opportunities grant to Vincent Gabriel and Jeff Biernaskie. Sarthak Sinah was supported by AI (2015), Alberta Children's Hospital Research Institute (2016) and Canadian Institutes of Health Research summer studentships. The Open Access Authors Fund of the University of Calgary provided support for publication costs.

Supplemental information: For reviewer comments and the original submission of this manuscript, please see www.cmajopen.ca/content/6/1/ E39/suppl/DC1. 